\title{
Interlaminar stabilization offers greater biomechanical advantage compared to interspinous stabilization after lumbar decompression: a finite element analysis
}

Teng $L u^{1,2}$ and $Y i L u^{1 *}$

\begin{abstract}
Background: Interlaminar stabilization and interspinous stabilization are two newer minimally invasive methods for lumbar spine stabilization, used frequently in conjunction with lumbar decompression to treat lumbar stenosis. The two methods share certain similarities, therefore, frequently being categorized together. However, the two methods offer distinct biomechanical properties, which affect their respective effectiveness and surgical success.

Objective: To compare the biomechanical characteristics of interlaminar stabilization after lumbar decompression (ILS) and interspinous stabilization after lumbar decompression (ISS). For comparison, lumbar decompression alone (DA) and decompression with instrumented fusion (DF) were also included in the biomechanical analysis.

Methods: Four finite element models were constructed, i.e., DA, DF, ISS, and ILS. To minimize device influence and focus on the biomechanical properties of different methods, Coflex device as a model system was placed at different position for the comparison of ISS and ILS. The range of motion (ROM) and disc stress peak at the surgical and adjacent levels were compared among the four surgical constructs. The stress peak of the spinous process, whole device, and device wing was compared between ISS and ILS.

Results: Compared with DA, the ROM and disc stress at the surgical level in ILS or ISS were much lower in extension. The ROM and disc stress at the surgical level in ILS were $1.27^{\circ}$ and $0.36 \mathrm{MPa}$, respectively, and in ISS $1.51^{\circ}$ and $0.55 \mathrm{MPa}$, respectively in extension. This is compared with $4.71^{\circ}$ and $1.44 \mathrm{MPa}$, respectively in DA. ILS (2.06-4.85 and $0.37-0.98$ $\mathrm{MPa}$, respectively) or ISS (2.07-4.78 and $0.37-0.98 \mathrm{MPa}$, respectively) also induced much lower ROM and disc stress at the adjacent levels compared with DF (2.50-7.20 and 0.37-1.20 MPa, respectively). ILS further reduced the ROM and disc stress at the surgical level by $8 \%$ and $25 \%$, respectively, compared to ISS. The stress peak of the spinous process in ILS was significantly lower than that in ISS (13.93-101 MPa vs. 31.08-172.5 MPa). In rotation, ILS yielded a much lower stress peak in the instrumentation wing than ISS (128.7 MPa vs. 222.1 MPa).

(Continued on next page)
\end{abstract}

\footnotetext{
*Correspondence: yilu1945@gmail.com

'Department of Neurosurgery, Brigham and Women's Hospital, Harvard Medical School, 60 Fenwood Rd, BTM 4th floor, Boston, MA 02115, USA

Full list of author information is available at the end of the article
}

(c) The Author(s). 2020 Open Access This article is licensed under a Creative Commons Attribution 4.0 International License, which permits use, sharing, adaptation, distribution and reproduction in any medium or format, as long as you give appropriate credit to the original author(s) and the source, provide a link to the Creative Commons licence, and indicate if changes were made. The images or other third party material in this article are included in the article's Creative Commons licence, unless indicated otherwise in a credit line to the material. If material is not included in the article's Creative Commons licence and your intended use is not permitted by statutory regulation or exceeds the permitted use, you will need to obtain permission directly from the copyright holder. To view a copy of this licence, visit http://creativecommons.org/licenses/by/4.0/. The Creative Commons Public Domain Dedication waiver (http://creativecommons.org/publicdomain/zero/1.0/) applies to the data made available in this article, unless otherwise stated in a credit line to the data. 
(Continued from previous page)

Conclusion: ILS and ISS partly address the issues of segmental instability in DA and hypermobility and overload at the adjacent levels in DF. ILS achieves greater segmental stability and results in a lower disc stress, compared to ISS. In addition, ILS reduces the risk of spinous process fracture and device failure.

Keywords: Lumbar spinal stenosis, Finite element, Biomechanics, Surgical decompression, Fusion, Interlaminar stabilization, Interspinous stabilization, Coflex device, Complication

\section{Background}

Surgical decompression with instrumented fusion (DF) has been commonly used to treat lumbar spinal stenosis (LSS), especially when it is associated with potential instability or deformity $[1,2]$. Compared with decompression alone (DA), the additional instrumented fusion procedure enhances the stability and reduces the incidence of iatrogenic instability and secondary stenosis at the surgical level [3, 4]. However, it is also associated with the risk of pseudarthrosis, nonunion, instrumentation failure, and adjacent segment disease [3-5]. In recent decades, interlaminar or interspinous stabilization has been introduced as an alternative to DA or DF, either as a stand-alone device or in conjunction with decompression. Biomechanically, these techniques partly simulate the kinematics of the surgical level and provide segmental stability in extension [6,7]. Until now, many interspinous stabilizing devices have been used for the treatment of LSS, such as X-STOP (Medtronic, MN, USA), WALLIS (Abbott Spine, TX, USA), and Superion (VertiFlex, San Clemente, CA, USA) [8-10]. Since first introduced in 1994, Coflex (Paradigm Spine, NY, USA) device, an interlaminar stabilization device, has been gaining popularity in clinical use [11-15]. Some studies have reported that decompression with Coflex stabilization achieves better outcomes than DA or DF, including a higher clinical success rate [12, 14, 15], more physiological kinematics [11, 12], a larger foraminal and disc height $[11,14,15]$, and less influence on adjacent segments [13].

Despite these merits, interspinous or interlaminar stabilization devices can induce some novel complications that are unique to this surgical procedure, such as spinous process fracture, device breakage, and dislodgment $[8,9,16]$. Regarding the Coflex device, the incidence of device-related complications has been reported in up to $24.4 \%$ of these patients [17]. In some severe cases, an additional fusion procedure is required to relieve the symptoms $[17,18]$. Excessive decompression, nonstandard operation, and osteoporosis have been considered causes of these complications [17-19]. Some studies have indicated that comparing with interlaminar positioning of the Coflex device, interspinous positioning might result in a greater stress load on the spinous process and therefore increase the incidence of device- related complications $[17,20]$, which implies that the interlaminar stabilization may be superior to the interspinous stabilization in the aspect of biomechanical performance. To the best of our knowledge, there is still a lack of biomechanical data to support this view and explain the mechanism.

Traditionally, the interlaminar devices and interspinous process devices are frequently categorized together $[8,21,22]$. Most previous studies have focused only on comparing interlaminar or interspinous device to other lumbar surgical techniques $[9,10,12,15,23]$, and few studies have focused on assessing whether the position of such device placement has an influence on biomechanical or clinical outcomes. In order to assess whether there is a fundamental difference in the biomechanical performance of the interlaminar device and interspinous process device, we comprehensively compared the biomechanical characteristics of DA, DF, decompression with interlaminar stabilization (ILS), and decompression with interspinous stabilization (ISS) by using the finite element (FE) methods. To minimize the specific device influence on the biomechanical evaluation, we used Coflex as a model system for the ILS and ISS comparison.

\section{Methods}

\section{Finite element (FE) modeling of the lumbar spine}

A nonlinear FE model of the L2-L5 lumbar spine was constructed (Fig. 1a). To create this model, thin layer $(0.625 \mathrm{~mm})$ computed tomography images (SOMATOM Definition Flash, Siemens, Inc., Muenchen, Germany) of the L2-L5 lumbar spine of a young healthy male were converted to a surface model using a medical imagebased engineering software (Mimics, Materialise, Inc., Leuven, Belgium). Solid models of the cortical shell, cancellous bone, and intervertebral discs were constructed using 3-Matic (Materialise, Inc., Leuven, Belgium). HyperMesh (Altair Engineering, Inc., Troy, MI, USA) was used for model meshing, and Abaqus (Hibbitt, Karlsson and Sorenson, Inc., Providence, RI, USA) was used for material property definition, model assembly, and FE analysis.

The thickness of the cortical shell and cartilage endplate was set as $1 \mathrm{~mm}$ and $0.5 \mathrm{~mm}$, respectively [24, 25]. The volume of the nucleus pulposus accounted for 

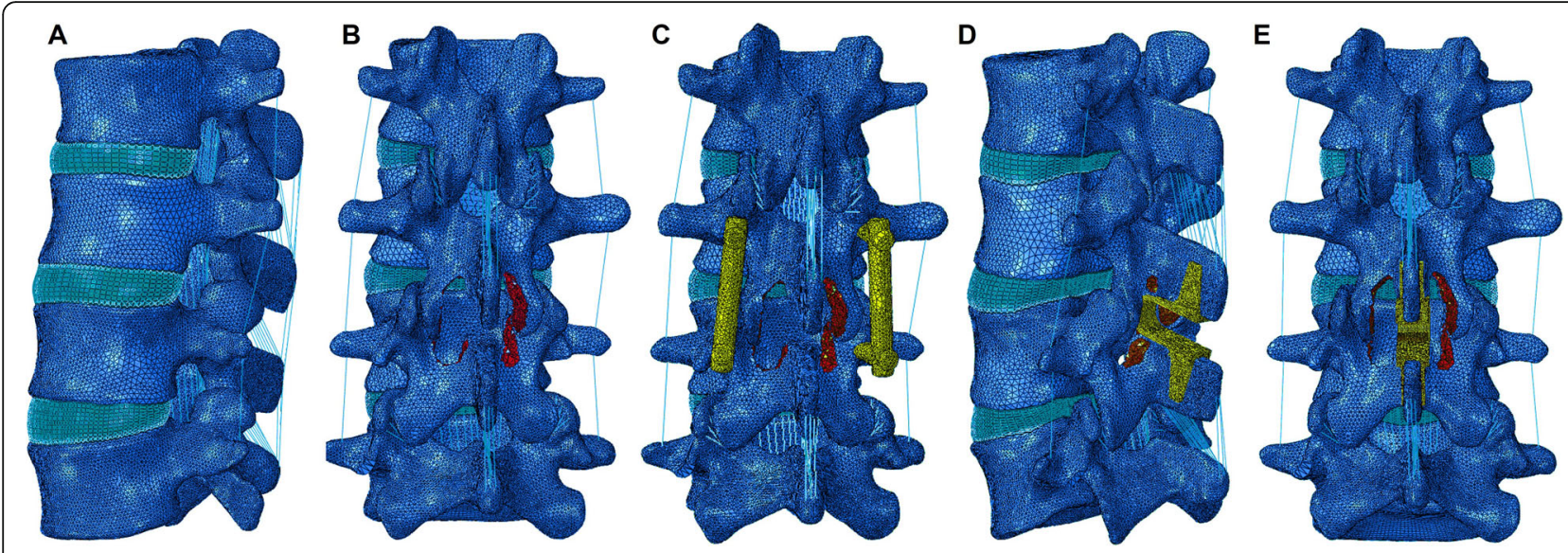

Fig. 1 FE models of a intact $L 2-5$ lumbar spine, b DA, c DF, and $\mathbf{d} I L S$ and e ISS

approximately $35 \%$ of the intact intervertebral disc [26]. The annulus fibrosus was modeled as a combination of annulus ground substance and annulus fibers. Eight layers of annulus fibers were defined as truss elements and embedded into the ground substance at an inclination of $\pm 25-35^{\circ}[26,27]$. The elastic strength of the annulus fibers proportionally decreased from the outermost layer $(550 \mathrm{MPa})$ to the innermost $(360 \mathrm{MPa})$ layer $[27,28]$. The ligaments constructed in the FE model were defined as truss elements that respond nonlinearly in tension only [27, 28]. Frictionless soft-contact between the articular processes was applied to mimic articular cartilage [29]. The bony tissues, nucleus pulposus, and the implants were modeled as elastic elements. The elements of the annulus ground substance were defined as hyperelastic. And hypoelastic material properties were assigned to the ligaments and annulus fibers. A convergence analysis was performed by ensuring the maximum changes in the strain energy $<5 \%$. The element types and the material properties used in this FE model were assigned based on previous publications, which are shown in Table $1[27,28]$.

\section{FE modeling of the surgical procedures}

In total, four surgical constructs were modeled and compared in this study, i.e., DA, DF, ILS, and ISS. Using

Table 1 Material properties assigned to the FE model

\begin{tabular}{|c|c|c|c|c|}
\hline Component & Element type & Young modulus (MPa) & Poisson ratio & Cross-sectional area $\left(\mathrm{mm}^{2}\right)$ \\
\hline \multicolumn{5}{|l|}{ Bone } \\
\hline Cortical bone & C3D4 & 12,000 & 0.3 & \\
\hline Cancellous bone & C3D4 & 100 & 0.2 & \\
\hline Cartilage endplate & C3D8 & 24 & 0.4 & \\
\hline \multicolumn{5}{|l|}{ Intervertebral disc } \\
\hline Nucleus pulpous & C3D8 & 1 & 0.49 & \\
\hline Annulus ground substance & $\mathrm{C} 3 \mathrm{D} 8 \mathrm{H}$ & Hyperelastic $(\mathrm{C} 10=0.18, \mathrm{C} 01=0.045)$ & & \\
\hline Annulus fibers & T3D2 & Hypoelastic (360-550 MPa) & & \\
\hline \multicolumn{5}{|l|}{ Ligaments } \\
\hline Anterior longitudinal & T3D2 & $15.6(<12 \%), 20(>12 \%)$ & & 63.7 \\
\hline Posterior longitudinal & T3D2 & $10(<11 \%), 20(>11 \%)$ & & 20 \\
\hline Ligamentum flavum & T3D2 & $15(<6.2 \%), 19.5(>6.2 \%)$ & & 40 \\
\hline Capsular & T3D2 & $7.5(<25 \%), 32.9(>25 \%)$ & & 30 \\
\hline Interspinous & T3D2 & $10(<20 \%), 11.6(>20 \%)$ & & 40 \\
\hline Supraspinous & T3D2 & $8.0(<20 \%), 15(>20 \%)$ & & 30 \\
\hline Intertransverse & T3D2 & $10(<18 \%), 58.7(>18 \%)$ & & 2 \\
\hline \multicolumn{5}{|l|}{ Implants } \\
\hline Coflex device, screws, and rods (titanium) & C3D4 & 110,000 & 0.3 & \\
\hline
\end{tabular}


Coflex device as a model, ILS and ISS models were constructed. For the surgical model of DA, bilateral decompression at L3/4 was simulated by removing the supraspinous ligament, interspinous ligament, ligamentum flavum, part of the laminar, and $50 \%$ of the medial facet (Fig. 1b) [7]. For the surgical model of DF, a screwrod fixation system was added at the surgical level after decompression (Fig. 1c). The diameter and length of the screw was $6.5 \mathrm{~mm}$ and $45 \mathrm{~mm}$, respectively. The diameter of the rod was $5.5 \mathrm{~mm}$. A "tie" constraint was assigned to the screw-rod and screw-bone interfaces to simulate the conditions of rigid fixation.

The geometry of the Coflex device was constructed based on the real product. A device with a suitable height $(10 \mathrm{~mm})$ was chosen and inserted into the interlaminar or interspinous space. Part of the spinous process was removed to provide sufficient space for Coflex implantation. The surface between the Coflex device and the bony tissues was defined as surface-tosurface contact. The coefficient of friction in the region where the wing contacted the spinous process was set to 0.8. A much lower coefficient of friction (0.1) was set for the rest of the contact region [7]. The ILS and ISS constructs were modeled by inserting the Coflex device into the interlaminar or interspinous space (Fig. 1d-e). For the surgical construct of ILS, the anterior portion of the Coflex device was located in the interlaminar space of the decompression level (Fig. 2a). In comparison, in the surgical construct of ISS, the whole "U" structure of the Coflex device was located in the interspinous space (Fig. $2 b)$.

\section{Loading conditions}

For all the FE models, the interior surface of L5 was constrained. A compressive load of $400 \mathrm{~N}$ was imposed on the superior surface of L2 to simulate physiological compressive loading [30]. For the intact FE model, another 8 $\mathrm{Nm}$ was applied to L2 to simulate flexion, extension, bending, and axial rotation [30]. For validation of the intact L2-L5 FE model, the segmental ROMs (L2/3, L3/4, and L4/5) were compared with the outcomes of previous biomechanical and FE publications [7, 30, 31]. For the surgical models, a hybrid method was applied, in which specific moments were applied to produce the same total ROMs of the intact FE model [7, 32].

\section{Results}

\section{Model validation}

The intersegmental ROMs of the intact FE model are listed in Table 2. The results are in accordance with those of previous publications (Fig. 3), suggesting that the intact L2-L5 FE model in the present study was successfully constructed and could be used for further modeling and analysis.

\section{Intersegmental ROM and disc stress peak}

The resulting intersegmental ROM and disc stress peak are shown in Table 2. Figure 4 shows the results that were normalized with respect to the intact model.

For the surgical segment (L3/4), the DF procedure resulted in the lowest ROM and disc stress peak in the four physiological motions. Compared with the intact model, the DF model showed values decreased by $69-$ $86 \%$ and $52-94 \%$, respectively. For the DA model, the $\mathrm{ROM}$ and disc stress peak did not change obviously in bending or rotation. However, in extension and flexion, the ROM increased by $63 \%$ and $29 \%$, respectively, and the disc stress peak increased by $85 \%$ and $9 \%$, respectively. The ROM and disc stress peak in bending and rotation in the ILS and ISS models were similar to those in the intact model. In extension, ISS reduced the ROM and disc stress peak by $48 \%$ and $29 \%$, respectively. Compared with ISS, ILS further decreased the ROM and disc stress peak by $8 \%$ and $25 \%$, respectively. In flexion, in both ILS and ISS model, the ROM and disc stress peak increased similarly by $28 \%$ and $7 \%$, respectively.

In the adjacent segments (L2/3 and L4/5), the DF model yielded the highest $\mathrm{ROM}$ and disc stress peak in the four motions. Compared with the intact model, the DF model showed ROM and disc stress peak values at the adjacent segments increased by $27-44 \%$ and $3-24 \%$, respectively. For the DA model, the ROM and disc stress peak did not change obviously in bending or rotation. However, in extension and flexion, the ROM and disc stress peak at the adjacent segments were reduced by 12 to $29 \%$ and -3 to $12 \%$, respectively. The ROM and disc stress peak in bending and rotation in the ILS and ISS models were similar to those in the intact model. In flexion, the two surgical models reduced the ROM and disc stress peak at the adjacent segments by $11-17 \%$ and $11-14 \%$, respectively. In extension, the ROM and disc stress peak at the adjacent segments were increased by $27-30 \%$ and $11-15 \%$, respectively.

\section{Stress peak of the spinous process and Coflex device}

Figure 5 shows the stress peak of the spinous process and Coflex device in the surgical constructs. The stress peak of the L3 spinous process was 13.93-71.02 MPa in ILS, which was much lower than that in ISS (34.57$159.9 \mathrm{MPa}$ ), especially in extension and rotation. The stress peak of the L4 spinous process was $25.4-101 \mathrm{MPa}$ in ILS, which was also lower than that in ISS (31.08172.5 MPa), especially in extension. The stress distributions of the L3 and L4 spinous processes are shown in Fig. 6.

The stress peak of the intact Coflex device was similar in ILS and ISS (19.63-207.7 MPa vs. 16.75-222.1 MPa). The stress peak of the Coflex wings in ILS and ISS was 19.63-212.7 MPa and $16.75-222.1 \mathrm{MPa}$, respectively. 


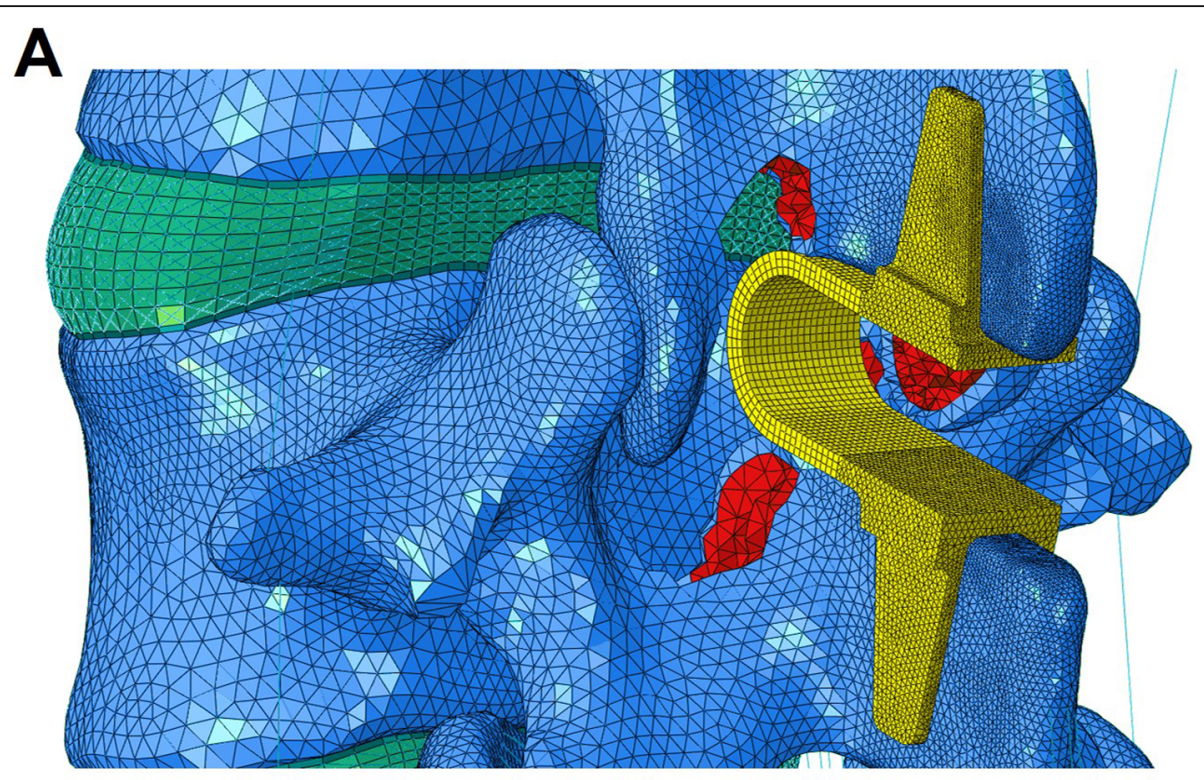

\section{B}

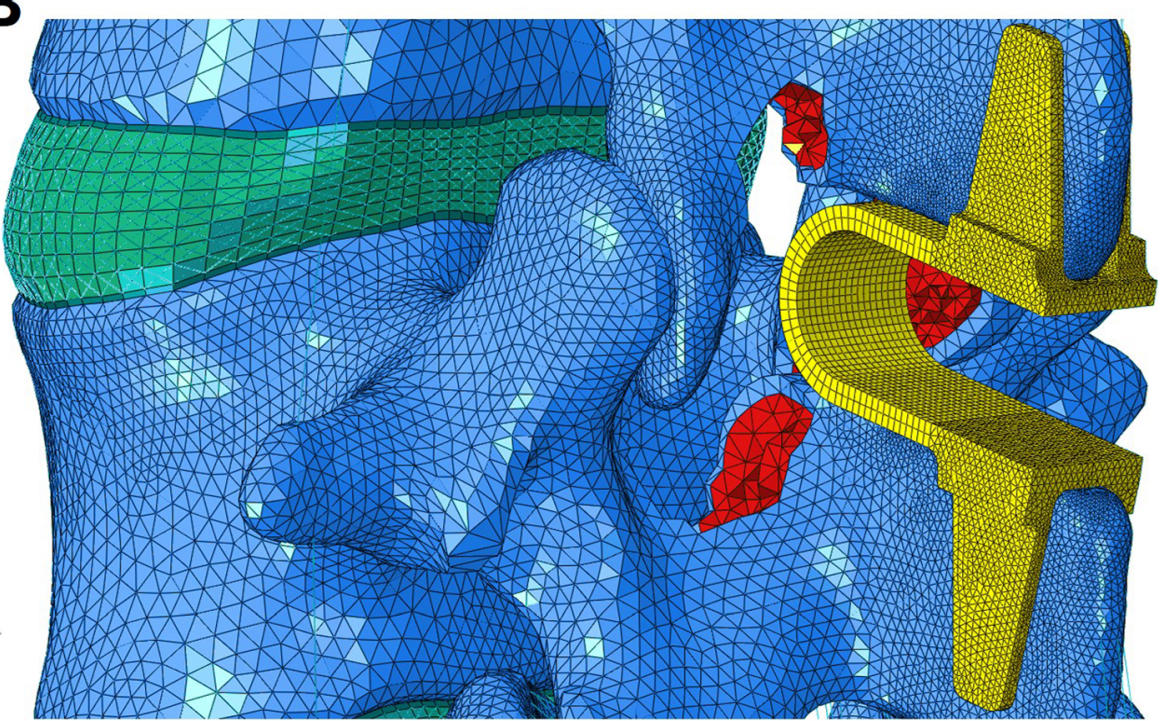

Fig. 2 a In ILS, the anterior portion of the Coflex device was inserted into the interlaminar space. b In ISS, the entire Coflex device was inserted into the interspinous space

The highest stress peak was found in the ISS model in rotation $(222.1 \mathrm{MPa})$, which was increased by $73 \%$ compared with that in the ILS model $(128.7 \mathrm{MPa})$. The stress distributions of the Coflex devices are shown in Fig. 7.

\section{Discussion}

In 1986, the first interspinous device named WALLIS was introduced [8]. After that, many interlaminar or interspinous devices have been developed $[8,33]$. The aim of using these devices in conjunction with lumbar decompression surgery is to enhance the stability after alleviating the nerve compression at the surgical level [8, 22, 33]. Due to the similar design theories, the interlaminar devices and the interspinous devices are commonly classified into one category [8, 21, 22]. However, the placing positions of the two types of device are much different. The interlaminar devices were designed to be inserted into the interlaminar space whereas the interspinous devices were placed between the adjacent spinous processes. Until now, few studies have attempted to assess the biomechanical difference between the two surgical constructs.

In the current FE study, we comprehensively compared the biomechanical characteristics of ILS and ISS to evaluate whether ILS is superior to ISS in terms of biomechanical performance. During the modeling 
Table 2 Intersegmental ROM and disc stress peak of the FE models

\begin{tabular}{|c|c|c|c|c|c|c|}
\hline & \multicolumn{3}{|c|}{ Intersegmental ROM $\left(^{\circ}\right)$} & \multicolumn{3}{|c|}{ Disc stress peak (MPa) } \\
\hline & $\mathrm{L} 2 / 3$ & L3/4 (surgical segment) & $\llcorner 4 / 5$ & $\mathrm{L} 2 / 3$ & L3/4 (surgical segment) & $\llcorner 4 / 5$ \\
\hline \multicolumn{7}{|c|}{ Extension } \\
\hline Intact & 2.68 & 2.88 & 3.75 & 0.73 & 0.78 & 0.72 \\
\hline DA & 1.91 & 4.71 & 2.99 & 0.69 & 1.44 & 0.74 \\
\hline DF & 3.86 & 0.41 & 5.35 & 0.89 & 0.06 & 0.82 \\
\hline ILS & 3.49 & 1.27 & 4.85 & 0.84 & 0.36 & 0.80 \\
\hline ISS & 3.42 & 1.51 & 4.78 & 0.83 & 0.55 & 0.80 \\
\hline \multicolumn{7}{|l|}{ Flexion } \\
\hline Intact & 3.92 & 4.42 & 5.31 & 0.76 & 0.70 & 0.76 \\
\hline DA & 3.27 & 5.68 & 4.69 & 0.66 & 0.76 & 0.65 \\
\hline DF & 5.24 & 1.12 & 7.20 & 0.88 & 0.57 & 0.88 \\
\hline ILS & 3.31 & 5.64 & 4.75 & 0.67 & 0.75 & 0.66 \\
\hline ISS & 3.27 & 5.65 & 4.69 & 0.66 & 0.75 & 0.65 \\
\hline \multicolumn{7}{|l|}{ Bending } \\
\hline Intact & 3.17 & 3.21 & 3.78 & 0.82 & 1.05 & 0.97 \\
\hline DA & 3.04 & 3.30 & 3.81 & 0.81 & 1.18 & 0.96 \\
\hline DF & 4.12 & 0.99 & 5.05 & 0.98 & 0.50 & 1.20 \\
\hline ILS & 3.12 & 3.12 & 3.92 & 0.83 & 1.08 & 0.98 \\
\hline ISS & 3.12 & 3.12 & 3.92 & 0.83 & 1.08 & 0.98 \\
\hline \multicolumn{7}{|l|}{ Rotation } \\
\hline Intact & 1.94 & 2.10 & 2.15 & 0.36 & 0.45 & 0.43 \\
\hline DA & 1.98 & 2.14 & 2.07 & 0.37 & 0.45 & 0.41 \\
\hline DF & 2.50 & 0.95 & 2.74 & 0.37 & 0.36 & 0.47 \\
\hline ILS & 2.06 & 1.99 & 2.14 & 0.37 & 0.48 & 0.42 \\
\hline ISS & 2.07 & 1.98 & 2.15 & 0.37 & 0.49 & 0.42 \\
\hline
\end{tabular}

ROM range of motion, DA decompression alone, DF decompression with fusion, ILS decompression with interlaminar stabilization, ISS decompression with interspinous stabilization

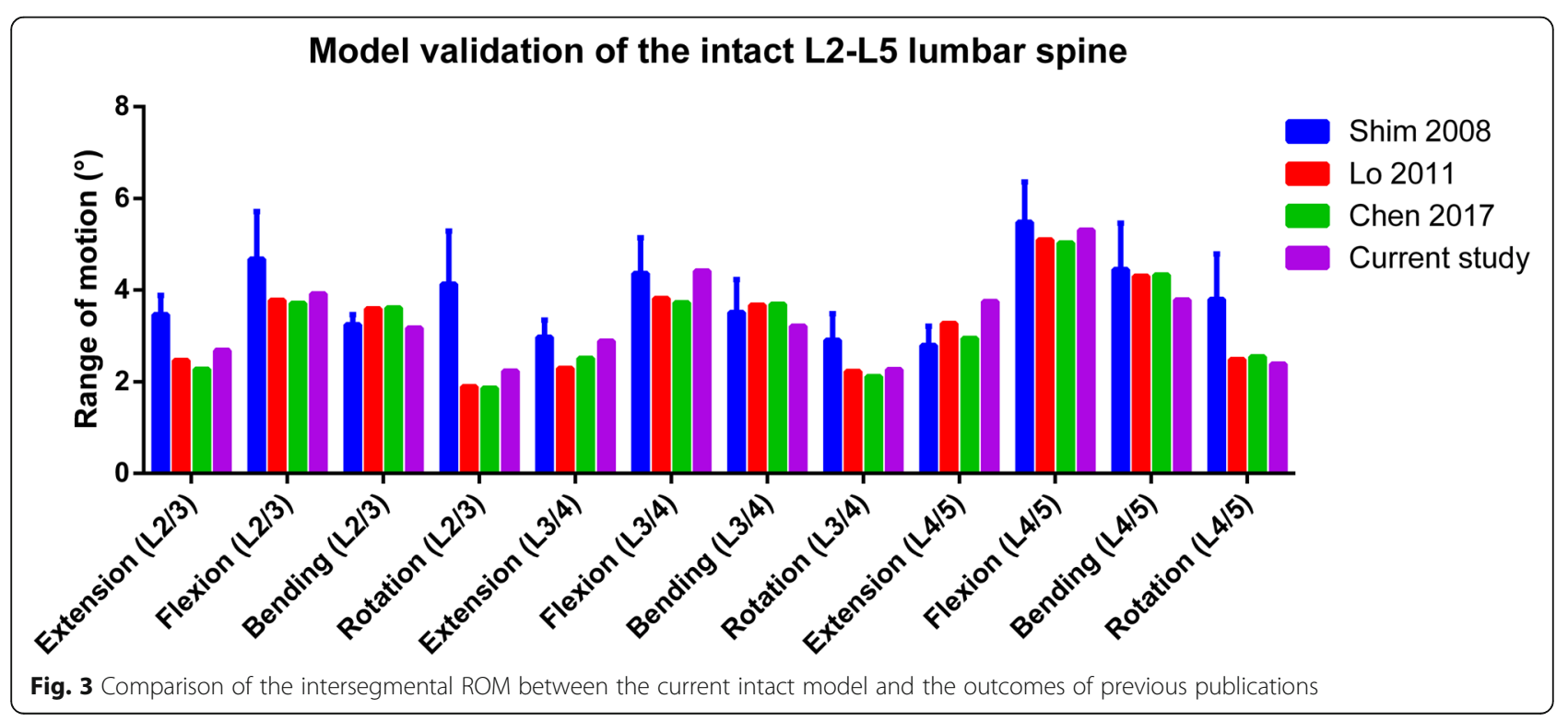




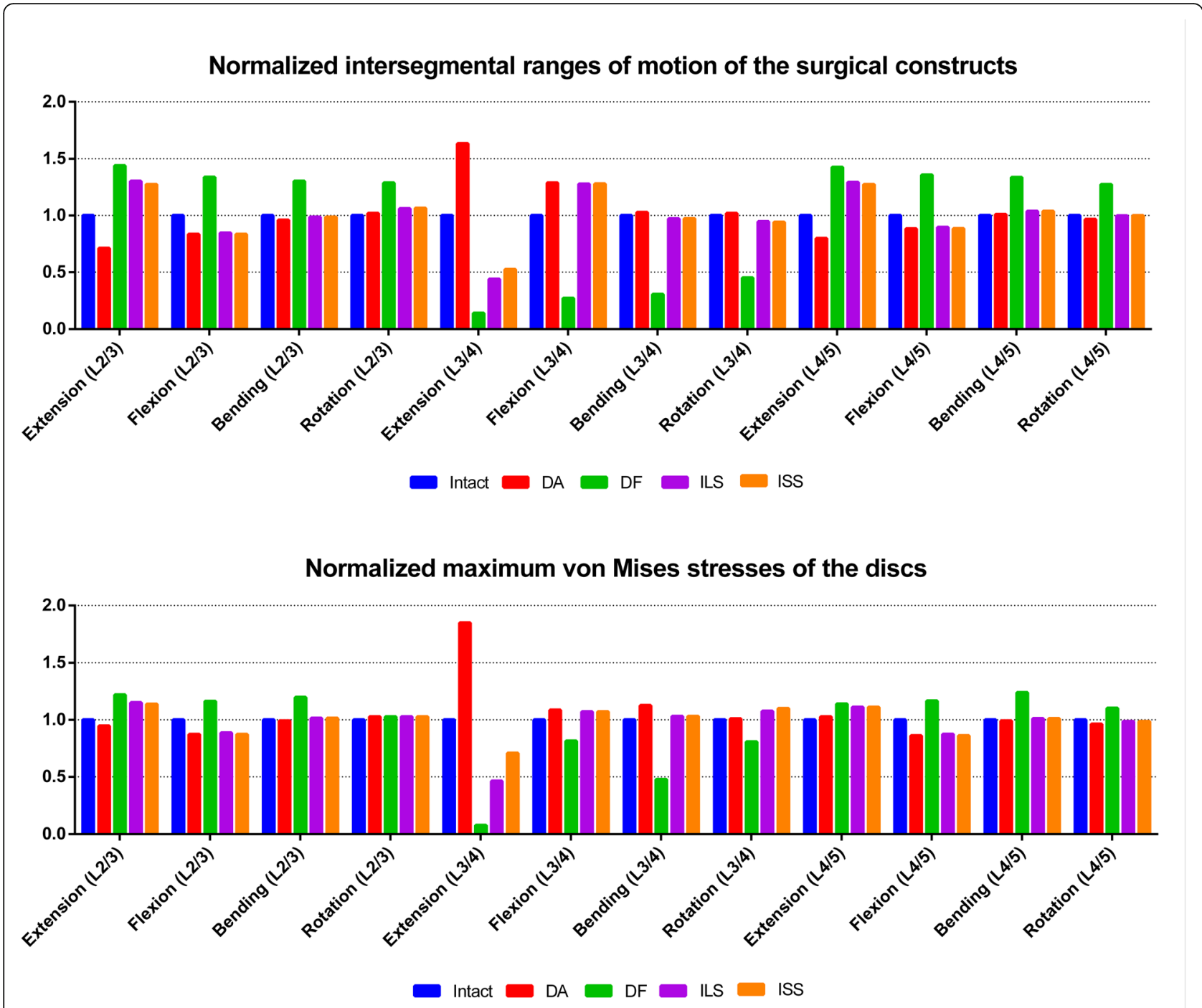

Fig. 4 Comparison of the normalized intersegmental range of motion (ROM) and disc stress peak among the intact, DA, DF, ILS, and ISS models

procedure, we used the same Coflex device at different position for the modeling of the ILS and ISS constructs to minimize the influence of the device design on the biomechanical evaluation but to focusing on the effect of the device location. The reason for choosing the Coflex device was that this implant could be inserted into both the interlaminar and interspinous spaces [8]. In addition, the Coflex device is one of the commonly used interlaminar or interspinous devices in surgeries [11-13]. Our results suggested that the interlaminar device and interspinous device have different biomechanical properties and should not be simply categorized together. Compared with ISS, ILS significantly reduces the stress level on the spinous process and also significantly reduces the stress on the hardware itself during spine rotation. In addition, ILS further significantly reduces the disc stress compared to ISS placement at the surgical level.
As shown in the results, both the ILS and ISS procedures provided the surgical level with stability in extension by reducing the segmental ROM and disc stress. Additionally, both surgical procedures effectively preserved the mobility of the surgical and adjacent levels in bending and rotation, compared to either DA or DF. The intersegmental ROM and disc stress peak were similar to those of the intact lumbar spine. However, in flexion, hypermobility and overload were observed at the surgical level, suggesting that the Coflex device could not provide strong biomechanical stability during flexion. This is mainly because the Coflex wings were crimped only to the spinous processes, and the effects of motion restriction in flexion are weak [6]. These results are in accordance with those of previous studies. Kulduk et al. conducted an FE study to assess the biomechanical performance of interlaminar device and found that the 


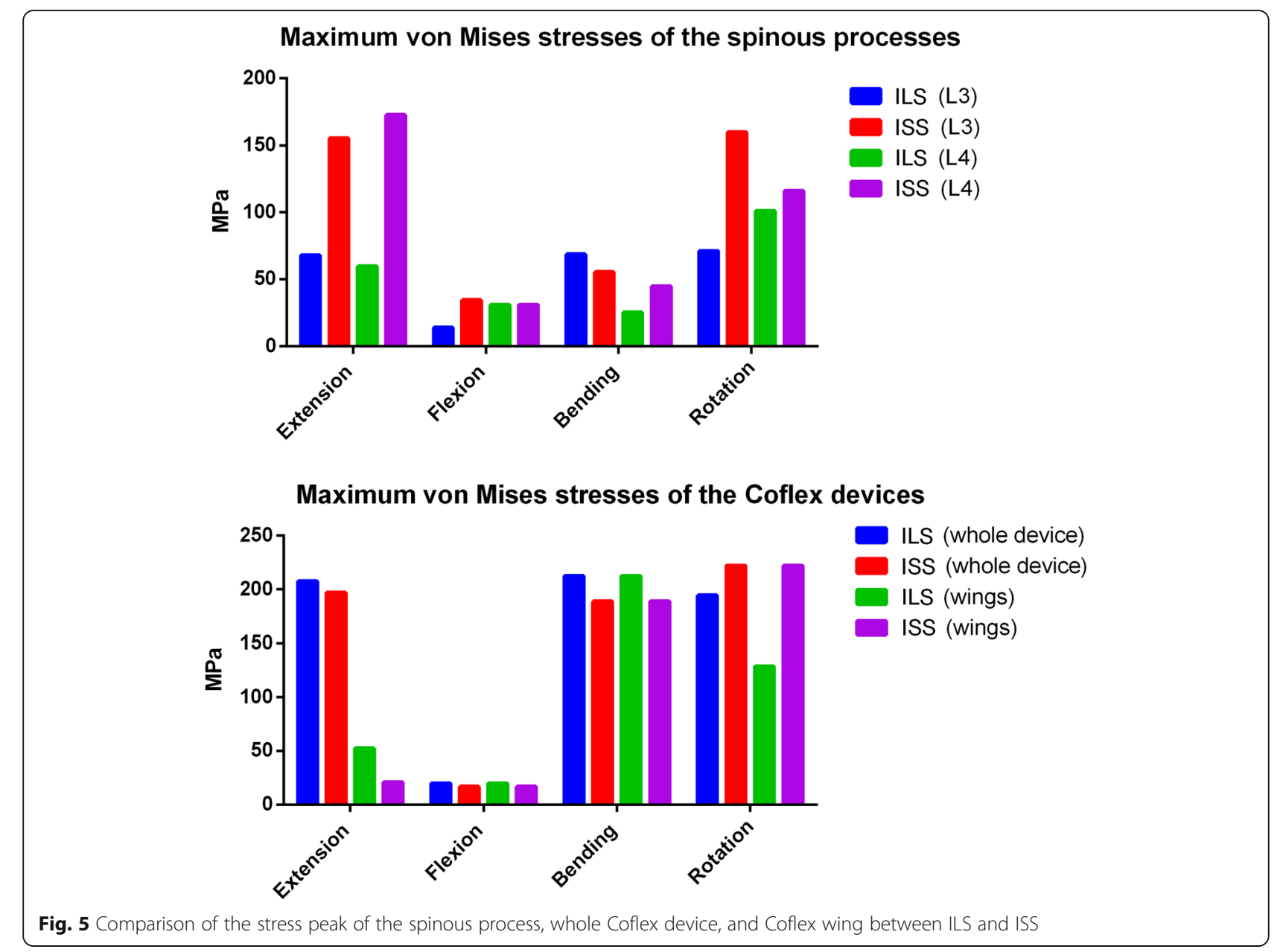

ROM at the surgical level was increased by $19 \%$ in flexion compared with that of the intact model [34]. Another FE study conducted by Lo et al. showed that the ROM and disc stress in the Coflex model were similar to those in the intact model in bending and rotation but much higher in flexion and lower in extension [7]. They concluded that Coflex device could effectively maintain the stability of the surgical level except in flexion [7]. Additionally, compared with the DF procedure, Coflex device has less biomechanical influence on the adjacent levels [7], which subsequently reduces the risk of adjacent segment degeneration $[7,12]$.

Compared with ISS, ILS further reduced the ROM and disc stress peak at the surgical level by $8 \%$ and $25 \%$, respectively, suggesting that the ILS procedure has a greater capacity to maintain the stability of the surgical level. The reason for this phenomenon may be that the interlaminar position of the Coflex device is closer to the rotational center of the surgical segment $[35,35]$. In flexion-extension, the rotational center of each segment has been reported to be mainly located in the posterior portion of the anterior column. Liu et al. used dual fluoroscopic imaging to measure the rotational center of L4/5 and L5/S1 in young adults [36]. The results showed that the rotational center in flexion-extension was located in the posterior quarter of the disc at L4/5 and near the posterior rim of the disc at L5/S1 [36]. A similar radiological study conducted by Aiyangar et al. showed that the average rotational center of each lumbar segment was located near the middle and posterior portions of the superior endplate [35]. Therefore, as the surgical segment extends, the ILS construct restricts the motion at an earlier stage because it is placed in the interlaminar space and thus closer to the rotational center. Meanwhile, a lower ROM in extension accordingly reduces the disc stress at the surgical level, which further decreased the risk of secondary degeneration $[7,12]$.

In addition, the ILS construct yielded much lower stress on the spinous process. In all motion directions, the average stress peak in the L3 and L4 spinous processes in the ISS construct was $96.15 \mathrm{MPa}$, which was approximately 1.75 times as high as that in the ILS construct $(54.8 \mathrm{MPa})$. The reason for these results may be that the load in the posterior column was mainly 


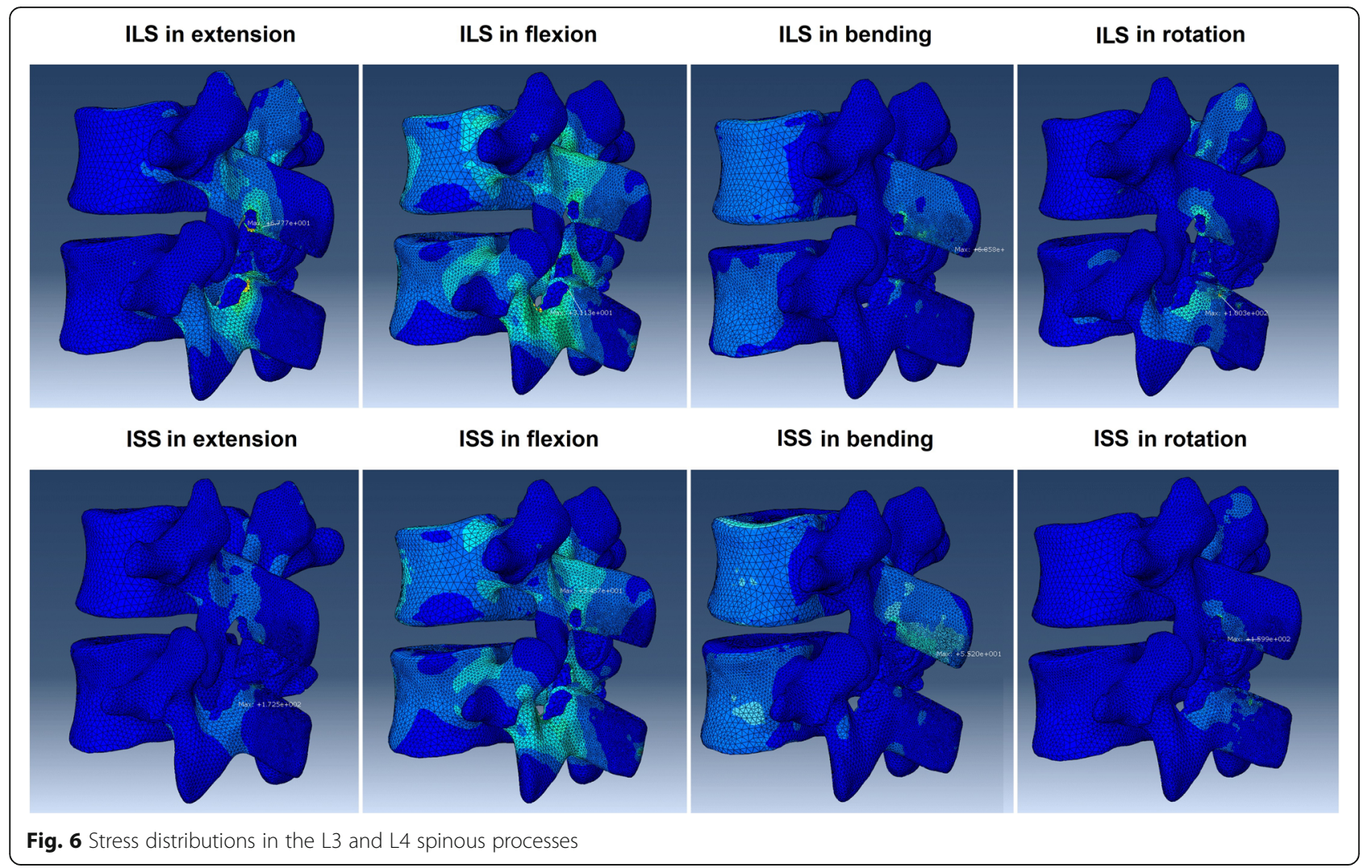

transferred onto the laminar in the ILS construct [20]. As shown in the stress nephogram of the posterior column (Fig. 6), the stress peak in the ILS construct was mainly located on the laminar facet, whereas the stress peak in the ISS construct was on the spinous process. Compared with the spinous process, the laminar facet has a much greater stiffness and mechanical strength $[20,37]$. A previous biomechanical study has reported that the laminar facet has a failure strength approximately five times higher than that of the spinous process $(1966 \mathrm{~N}$ vs. $405 \mathrm{~N})$, and thus has a greater capacity to resist fracture [37]. Additionally, the laminar facet offers a greater contact area for the Coflex device due to its wider dimension. Due to these advantages, the ILS construct results in a more homogeneous stress distribution in the posterior column and thus carries less risk of inducing spinous process fracture than the ISS construct $[20,38]$.

Regarding the stress peak of the Coflex device, the value was similar in ILS and ISS. However, for the wing structure, ISS yielded a much higher stress peak in rotation than did ILS (222.1 MPa vs. 128.7 MPa). The reason for this phenomenon may also be that the Coflex device in the ISS construct is farther away from the rotational center of the surgical segment $[35,36]$. Since the ROM was similar in ILS and ISS in rotation, the ISS construct resulted in larger deformation of the wing structures and subsequently a greater stress load to resist segmental motion. In addition, due to the design features, the Coflex wing has much less fatigue strength than the Coflex U arm [20]. All of these disadvantages result in ISS increasing the risk of Coflex wing breakage; thus, the Coflex device should be inserted into the interlaminar space to avoid high stress concentration on the wings.

For the DA and DF procedures, the results of the current study showed that they significantly changed the biomechanical characteristics of the lumbar spine, which is in accordance with the findings of previous studies [7, 39]. Lo et al. performed an FE study to assess the biomechanical performance of different fusion techniques in treating lumbar spinal stenosis and found that the conventional fusion procedure increased the ROM at the adjacent levels by $21-44 \%$ in all motion directions [39]. For the DA procedure, another FE study conducted by Lo et al. showed that the ROM at the surgical level was increased by $13 \%$ and $64 \%$ in flexion and extension, respectively [7]. Meanwhile, in the same motion directions, the disc stress peak at the surgical level was $10 \%$ and $100 \%$ greater than that in the intact model in flexion and extension, respectively [7].

Our results showed that the use of ILS or ISS partly addresses the issue of segmental instability in the DA model. Both the two surgical procedures enhance the stability and reduce the load on the anterior column at the surgical level in extension, especially in ILS. These 


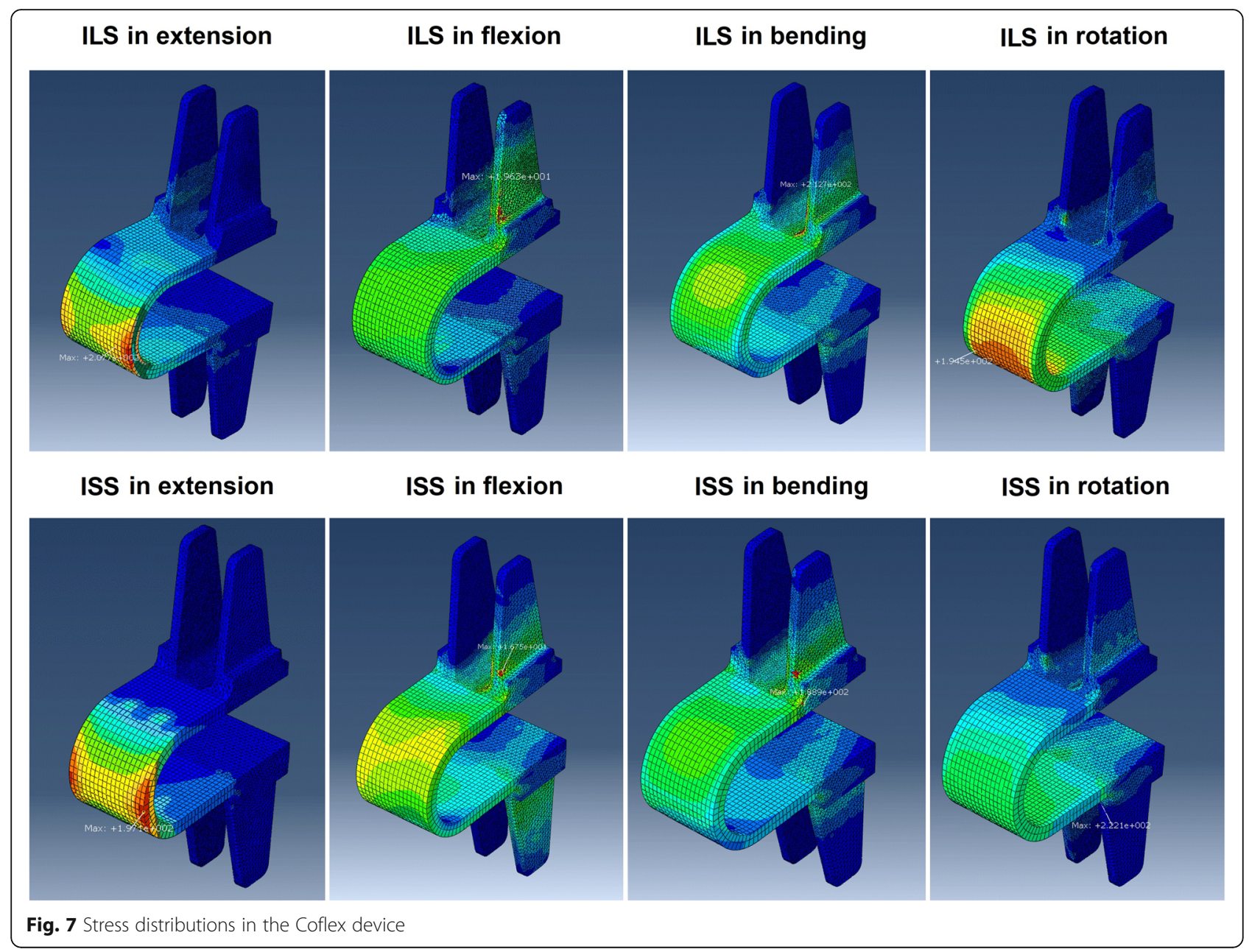

advantages may facilitate the achievement of better clinical outcomes in treating lumbar spinal stenosis. Schmidt et al. reported the clinical outcomes of DA and ILS in treating symptomatic lumbar spinal stenosis after 2 years [15]. The results showed that the clinical success rate was much higher in the ILS group ( $58.4 \%$ vs. $41.7 \%$ ) [15]. A similar study conducted by Kumar et al. also showed that patients treated with ILS showed greater recovery of symptoms than those treated with decompression alone [14]. In addition, due to the strong support in the posterior column, the foraminal and disc height in the group treated with ILS were well maintained [14].

Meanwhile, ILS or ISS alleviated the hypermobility and overload at the adjacent levels compared with DF, which might subsequently reduce the risk of adjacent segment degeneration [7, 12]. In an FE study conducted by Shen et al., the results showed that DF significantly increased the ROM at the adjacent levels by $17.7-61.4 \%$, which was much higher than those in ILS and ISS [22]. In addition, DF yielded much higher disc stress and facet joint stress at the adjacent levels than ILS and ISS [22]. Bae et al. retrospectively compared the clinical outcomes of using ILS and DF for treating lumbar spinal stenosis [12]. The results showed that the rate of composite clinical success at the treated level was similar in the ILS and DF groups (64.5\% vs. $69.7 \%)$ and that both surgical procedures could provide sufficient stability at the treated level [12]. However, at the adjacent level, the DF procedure increased the angular motion by a mean of $1.42^{\circ}$, whereas the ILS procedure effectively maintained the normal kinematics [12]. The author considered that the more physiological mobility at the adjacent level could prevent segmental degeneration in ILS patients [12].

There exist some limitations in this study. First, the intact FE model was construct based on the computed tomography data from a young healthy man, which might underestimate the influence of severe degenerative pathologies on the biomechanical performance of the lumbar spine, such as severe osteoporosis, scoliosis, and significant losses of the disc height and segment lordosis. In addition, some other interlaminar and interspinous devices could be compared in the future to further understand the difference of the biomechanical properties between ILS and ISS. 


\section{Conclusion}

The ILS or ISS construct preserves better the biomechanical characteristics of the intact lumbar spine compared to the DA and DF constructs and partly addresses the issues of the DA construct in segmental instability and the DF construct in hypermobility and overload at the adjacent levels. Compared to the ISS construct, the ILS construct reduces the stress on the spinous process and on the device itself, potentially minimizing the possible complications. In addition, the ILS construct further reduces the disc stress or excessive range of motion at the surgical level, providing a greater capacity to maintain the natural integrity of the operated spine.

\section{Abbreviations}

DA: Decompression alone; DF: Decompression with fusion;

ILS: Decompression with interlaminar stabilization; ISS: Decompression with interspinous stabilization; ROM: Range of motion; FE: Finite element; LSS: Lumbar spinal stenosis

\section{Acknowledgements}

Not applicable.

\section{Authors' contributions}

$T L$ designed, acquired, and analyzed the data and drafted the paper. YL designed the project, supervised the research, and revised the paper critically for submission. The author(s) read and approved the final manuscript.

\section{Funding}

No funding required for the study.

\section{Availability of data and materials}

All data generated or analyzed during this study are included in this published article.

\section{Ethics approval and consent to participate}

Not applicable

\section{Consent for publication}

Not applicable

\section{Competing interests}

The authors declare that they have no competing interests.

\section{Author details}

'Department of Neurosurgery, Brigham and Women's Hospital, Harvard Medical School, 60 Fenwood Rd, BTM 4th floor, Boston, MA 02115, USA. ${ }^{2}$ Department of Orthopedics, Xi'an Jiaotong University Second Affiliated Hospital, Xi'an, China.

Received: 27 March 2020 Accepted: 22 July 2020

Published online: 29 July 2020

\section{References}

1. Kepler CK, Vaccaro AR, Hilibrand AS, Anderson DG, Rihn JA, Albert TJ, et al. National trends in the use of fusion techniques to treat degenerative spondylolisthesis. Spine (Phila Pa 1976). 2014;39(19):1584-9.

2. Bae HW, Rajaee SS, Kanim LE. Nationwide trends in the surgical management of lumbar spinal stenosis. Spine (Phila Pa 1976). 2013;38(11): 916-26.

3. Ghogawala Z, Dziura J, Butler WE, Dai F, Terrin N, Magge SN, et al. Laminectomy plus fusion versus laminectomy alone for lumbar spondylolisthesis. N Engl J Med. 2016;374(15):1424-34.

4. Forsth P, Olafsson G, Carlsson T, Frost A, Borgstrom F, Fritzell P, et al. A randomized, controlled trial of fusion surgery for lumbar spinal stenosis. $\mathrm{N}$ Engl J Med. 2016;374(15):1413-23.
5. Chun DS, Baker KC, Hsu WK. Lumbar pseudarthrosis: a review of current diagnosis and treatment. Neurosurg Focus. 2015;39(4):E10.

6. Kettler A, Drumm J, Heuer F, Haeussler K, Mack C, Claes L, et al. Can a modified interspinous spacer prevent instability in axial rotation and lateral bending? A biomechanical in vitro study resulting in a new idea. Clin Biomech (Bristol, Avon). 2008;23(2):242-7.

7. Lo CC, Tsai KJ, Chen SH, Zhong ZC, Hung C. Biomechanical effect after Coflex and Coflex rivet implantation for segmental instability at surgical and adjacent segments: a finite element analysis. Comput Methods Biomech Biomed Engin. 2011;14(11):969-78.

8. Pintauro M, Duffy A, Vahedi P, Rymarczuk G, Heller J. Interspinous implants: are the new implants better than the last generation? A review. Curr Rev Musculoskelet Med. 2017;10(2):189-98.

9. Zhao XW, Ma JX, Ma XL, Li F, He WW, Jiang X, et al. Interspinous process devices(IPD) alone versus decompression surgery for lumbar spinal stenosis(LSS): a systematic review and meta-analysis of randomized controlled trials. Int J Surg. 2017:39:57-64.

10. Mo Z, Li D, Zhang R, Chang M, Yang B, Tang S. Comparative effectiveness and safety of posterior lumbar interbody fusion, Coflex, Wallis, and X-stop for lumbar degenerative diseases: a systematic review and network metaanalysis. Clin Neurol Neurosurg. 2018;172:74-81.

11. Lee N, Shin DA, Kim KN, Yoon DH, Ha Y, Shin HC, et al. Paradoxical radiographic changes of Coflex interspinous device with minimum 2-year follow-up in lumbar spinal stenosis. World Neurosurg. 2016;85:177-84.

12. Bae HW, Lauryssen C, Maislin G, Leary S, Musacchio MJ Jr. Therapeutic sustainability and durability of coflex interlaminar stabilization after decompression for lumbar spinal stenosis: a four year assessment. Int J Spine Surg. 2015;9:15.

13. Liu $X$, Liu $Y$, Lian $X, X u$ J. Magnetic resonance imaging on disc degeneration changes after implantation of an interspinous spacer and fusion of the adjacent segment. Int J Clin Exp Med. 2015;8(4):6097-102.

14. Kumar N, Shah SM, Ng YH, Pannierselvam VK, Dasde S, Shen L. Role of coflex as an adjunct to decompression for symptomatic lumbar spinal stenosis. Asian Spine J. 2014;8(2):161-9.

15. Schmidt S, Franke J, Rauschmann M, Adelt D, Bonsanto MM, Sola S. Prospective, randomized, multicenter study with 2-year follow-up to compare the performance of decompression with and without interlaminar stabilization. J Neurosurg Spine. 2018;28(4):406-15.

16. Poetscher AW, Gentil AF, Ferretti M, Lenza M. Interspinous process devices for treatment of degenerative lumbar spine stenosis: a systematic review and meta-analysis. PLoS One. 2018;13(7):e0199623.

17. Davis R, Auerbach JD, Bae H, Errico TJ. Can low-grade spondylolisthesis be effectively treated by either coflex interlaminar stabilization or laminectomy and posterior spinal fusion? Two-year clinical and radiographic results from the randomized, prospective, multicenter US investigational device exemption trial: clinical article. J Neurosurg Spine. 2013;19(2):174-84.

18. Zang L, Du P, Hai Y, Su QJ, Lu SB, Liu T. Device related complications of the Coflex interspinous process implant for the lumbar spine. Chin Med J (Engl). 2013;126(13):2517-22.

19. Xu C, Ni WF, Tian NF, Hu XQ, Li F, Xu HZ. Complications in degenerative lumbar disease treated with a dynamic interspinous spacer (Coflex). Int Orthop. 2013;37(11):2199-204.

20. Trautwein FT, Lowery GL, Wharton ND, Hipp JA, Chomiak RJ. Determination of the in vivo posterior loading environment of the Coflex interlaminarinterspinous implant. Spine J. 2010;10(3):244-51.

21. Wilke HJ, Drumm J, Haussler K, Mack C, Steudel WI, Kettler A. Biomechanical effect of different lumbar interspinous implants on flexibility and intradiscal pressure. Eur Spine J. 2008;17(8):1049-56.

22. Shen H, Fogel GR, Zhu J, Liao Z, Liu W. Biomechanical analysis of different lumbar interspinous process devices: a finite element study. World Neurosurg. 2019;127:e1112-9.

23. Gu H, Chang Y, Zeng S, Zheng X, Zhang R, Zhan S, et al. Wallis interspinous spacer for treatment of primary lumbar disc herniation: three-year results of a randomized controlled trial. World Neurosurg. 2018;120:e1331-6.

24. Guo TM, Lu J, Xing YL, Liu GX, Zhu HY, Yang L, et al. A 3-Dimensional finite element analysis of adjacent segment disk degeneration induced by transforaminal lumbar interbody fusion after pedicle screw fixation. World Neurosurg. 2018.

25. Zhang Z, Fogel GR, Liao Z, Sun Y, Liu W. Biomechanical analysis of lateral lumbar interbody fusion constructs with various fixation options: based on a validated finite element model. World Neurosurg. 2018;114:e1120-9. 
26. Zhao X, Du L, Xie YZ, Zhao J. Effect of lumbar lordosis on the adjacent segment in transforaminal lumbar interbody fusion: a finite element analysis. World Neurosurg. 2018;114:E114-20.

27. Ruberte LM, Natarajan RN, Andersson GBJ. Influence of single-level lumbar degenerative disc disease on the behavior of the adjacent segments-a finite element model study. J Biomech. 2009:42(3):341-8.

28. Kim HJ, Kang KT, Chang BS, Lee CK, Kim JW, Yeom JS. Biomechanical analysis of fusion segment rigidity upon stress at both the fusion and adjacent segments: a comparison between unilateral and bilateral pedicle screw fixation. Yonsei Med J. 2014;55(5):1386-94.

29. Wang L, Zhang B, Chen S, Lu X, Li ZY, Guo Q. A validated finite element analysis of facet joint stress in degenerative lumbar scoliosis. World Neurosurg. 2016;95:126-33.

30. Shim CS, Park SW, Lee SH, Lim TJ, Chun K, Kim DH. Biomechanical evaluation of an interspinous stabilizing device. Locker. Spine (Phila Pa 1976). 2008;33(22):E820-7.

31. Chen HC, Wu JL, Huang SC, Zhong ZC, Chiu SL, Lai YS, et al. Biomechanical evaluation of a novel pedicle screw-based interspinous spacer: a finite element analysis. Med Eng Phys. 2017;46:27-32.

32. Panjabi MM. Hybrid multidirectional test method to evaluate spinal adjacent-level effects. Clin Biomech (Bristol, Avon). 2007;22(3):257-65.

33. Gala RJ, Russo GS, Whang PG. Interspinous implants to treat spinal stenosis. Curr Rev Musculoskelet Med. 2017;10(2):182-8.

34. Kulduk A, Altun NS, Senkoylu A. Biomechanical comparison of effects of the Dynesys and Coflex dynamic stabilization systems on range of motion and loading characteristics in the lumbar spine: a finite element study. Int J Med Robot. 2015;11(4):400-5.

35. Aiyangar A, Zheng L, Anderst W, Zhang X. Instantaneous centers of rotation for lumbar segmental extension in vivo. J Biomech. 2017;52:113-21.

36. Liu Z, Tsai TY, Wang S, Wu M, Zhong W, Li JS, et al. Sagittal plane rotation center of lower lumbar spine during a dynamic weight-lifting activity. J Biomech. 2016;49(3):371-5.

37. Wenger DR. Evaluation of fixation sites for segmental instrumentation of the human vertebra. Orthop Trans. 1982;6:23-4.

38. Kumar N, Judith MR, Kumar A, Mishra V, Robert MC. Analysis of stress distribution in lumbar interbody fusion. Spine (Phila Pa 1976). 2005;30(15): $1731-5$.

39. Lo CC, Tsai KJ, Zhong ZC, Chen SH, Hung C. Biomechanical differences of Coflex-F and pedicle screw fixation combined with TLIF or ALIF--a finite element study. Comput Methods Biomech Biomed Engin. 2011;14(11):94756.

\section{Publisher's Note}

Springer Nature remains neutral with regard to jurisdictional claims in published maps and institutional affiliations.

Ready to submit your research? Choose BMC and benefit from:

- fast, convenient online submission

- thorough peer review by experienced researchers in your field

- rapid publication on acceptance

- support for research data, including large and complex data types

- gold Open Access which fosters wider collaboration and increased citations

- maximum visibility for your research: over $100 \mathrm{M}$ website views per year

At $\mathrm{BMC}$, research is always in progress.

Learn more biomedcentral.com/submissions 